\title{
Spatiotemporal changes in relative rat (Rattus rattus) abundance following large-scale pest control
}

\author{
James W. Griffiths ${ }^{1 \dagger}$ and Mandy C. Barron ${ }^{2 * \dagger}$ \\ ${ }^{1}$ Department of Conservation, 18-32 Manners Street, PO Box 10-420, Wellington 6143, New Zealand \\ ${ }^{2}$ Landcare Research, Lincoln, PO Box 69040, Lincoln 7640, New Zealand \\ *Author for correspondence (Email: barronm@landcareresearch.co.nz) \\ ${ }^{\dagger}$ These authors contributed equally
}

Published online: 11 March 2016

\begin{abstract}
We examined spatiotemporal changes in rat tracking indices following large-scale ( $>10000$ ha) pest control using aerial applications of sodium monofluoroacetate (1080) baits in Tararua Forest Park, North Island, New Zealand. Population control of rats appeared effective, with few to no rat tracks recorded in treatment areas during the 6 months after control. However, the rat tracking index increased rapidly after that, and 24-30 months after control, rat tracking indices in treated areas exceeded those in the non-treated areas. Rat tracking indices first increased at the treatment margins (6-12 months post-control), with rat recovery in the centre of controlled areas delayed by 24-30 months. The best supported statistical model of rat tracking indices included an interaction term between time since treatment*distance to non-treatment area, which indicated that overall increases in rat tracking after control were highest at monitoring lines located in the interior of the control zone, with a negative growth rate estimated for lines located outside of the control area. This suggests a competitive release for rat populations in the interior of the control zone. The observed delay in rat recovery on the interior lines compared with lines located at the control margin implies that rat population increase following control was initiated by rats migrating into the treated area from adjacent untreated forest areas. Treatment persistence, therefore, might be increased by increasing the size of pest control areas; aligning pest control boundaries with immigration barriers, such as large water bodies and/or alpine zones; or implementing intensive pest control around treatment boundaries to intercept immigrating rats.
\end{abstract}

Keywords: 1080; lags; immigration; rat tracking index; rate of increase; treatment persistence

\section{Introduction}

Effective large-scale (>10 000 ha) control of rats (Rattus rattus) in remote, and often mountainous, forest areas of New Zealand is now possible due to advances in the aerial application of cereal baits containing the toxin sodium monofluoroacetate (1080) (Innes et al. 1995). Effective control is necessary to prevent declines or extinctions of native species that are vulnerable to rat predation (Miller \& Anderson 1992; Innes et al. 1999; Powlesland et al. 1999, 2000; Elliott \& Suggate 2007; Ruscoe et al. 2013). However, because rat populations can recover within two years of control (Innes et al. 1995), vulnerable species are only temporarily released from predation pressure. Frequent (c. 3-yearly) reapplications of 1080 are therefore necessary to sustain reductions in rat predation pressure (Innes et al. 1999; Brown \& Urlich 2005; Elliott \& Suggate 2007; Ruscoe et al. 2013). If it was possible to prolong treatment persistence, significant cost savings could be made by reducing the frequency of 1080 applications, and ecological outcomes would be enhanced.

After control, pest populations recover through immigration and in situ breeding. Determining the relative contributions of these modes of pest population recovery will inform management strategies. If immigration is the main contributor to pest population recovery after control, optimal pest control strategies might include scaling up the size of pest control areas to slow the rate of pest recovery in the core of control areas, aligning pest control boundaries with immigration barriers, such as large water bodies or alpine zones, or implementing intensive pest control around the perimeter of control areas to intercept immigrating pests. In contrast, if pest recovery after control is primarily driven by in situ breeding, optimal pest control would focus on reducing the number of pests that survive pest control.

Optimal pest control strategies must also consider the influence of food availability on pest populations. Food availability can be an important determinant of rat population growth in New Zealand forests (Blackwell et al. 2003; Dilks et al. 2003; Innes 2005; Sweetapple \& Nugent 2007; King \& Powell 2011). Thus, the availability of preferred foods (fruit, seeds and invertebrates) is likely to influence the length of time that rodent abundance is reduced after control (Studholme 2000; Sweetapple \& Nugent 2007).

This study documents spatiotemporal changes in relative rat abundance following the aerial application of 1080 baits to two treatment areas in mixed podocarp-broadleaved-beech forest, 22000 and 10000 ha in size, within the Tararua Forest Park. Conditional on an effective control, we predicted the recovery in rat abundance would start first at the outer margins of the controlled area due to reinvasion from the surrounding uncontrolled forest. However, we predicted rates of population increase would be fastest in the interior of the controlled area due to a lack of competitors (possums and other rats). We also expected to observe a positive effect of beech (Fuscospora cliffortioides, F. fusca, F. truncata, and Lophozonia menziesii) mast seedfall (high food availability) on the rates of rat increase. To test these predictions, we modelled the relative abundance of rats as a function of time since treatment, distance from treatment boundary, relative possum abundance, elevation, forest type, season, and beech mast seedfall. 


\section{Methods}

\section{Study site}

The study was undertaken in central and southern portions of the Tararua Forest Park $\left(41^{\circ} 00^{\prime}-40^{\circ} 30^{\prime} \mathrm{S}\right.$ and $175^{\circ} 11^{\prime}$ $\left.-175^{\circ} 30^{\prime} \mathrm{E}\right)$, north of Wellington, New Zealand. The area is mountainous and composed almost entirely of uplifted shattered greywacke and calcareous siltstone (Foley 1984). Valley floors and low-elevation terraces are dominated by Podocarpaceae: matāi (Prumnopitys taxifolia), miro (P. ferruginea), kahikatea (Dacrycarpus dacrydioides), and rimu (Dacrydium cupressinum). These are interspersed with hīnau, red beech (Fuscospora fusca), rewarewa (Knightia excelsa), tawa (Beilschmiedia tawa), and emergent rātā (Metrosideros robusta). Mid-slopes are dominated by kāmahi (Weinmannia racemosa), and red and silver beech (Lophozonia menziesii). Higher elevation forest at or near the treeline is predominantly silver and mountain beech (Fuscospora cliffortioides). Above the treeline tussock grasslands (Chionochloa spp.) prevail (Druce 1961).

\section{Experimental design}

The study comprised a non-treatment area and two treatment areas (Fig. 1), characterised by similar forest types, weather and soils (Leathwick 2002). Treatment area 1 comprised c. 22000 ha from Mount Holdsworth to Otaki Forks that was treated in November 2010 and December 2013 with aerial applications of cereal prefeed (non-toxic baits) followed by toxic 1080 cereal baits at sowing rates of $2 \mathrm{~kg} \mathrm{ha}^{-1}$ on a 3 -year cycle. Treatment area 2 comprised c. 10000 ha within the Hutt Water Catchment that was treated in May 2009 with the same aerial regime of prefeed, followed by toxic 1080 baits at a $2 \mathrm{~kg} \mathrm{ha}^{-1}$ sowing rate but on a 5 -year cycle. Treatment was last applied to the Hutt Catchment in November 2014. The non-treatment area, the balance of the Tararua Forest Park (c. $37930 \mathrm{ha}$ ), has received no treatment since 2007.

\section{Rat sampling method}

An index of rat abundance was derived using the rat footprint tracking tunnel method described by Gillies and Williams (2013). Following this method, 65 lines of tracking tunnels, each comprising ten Philproof (Philproof Pest Control, Hamilton) roto-moulded plastic tracking tunnels spaced at $50-\mathrm{m}$ intervals, were deployed in non-treatment and treatment areas following two layouts.

\section{Layout 1}

Clusters of five tracking tunnel lines were installed in each of eleven $2-2.5-\mathrm{km}$ radius sampling zones in the non-treatment and treatment areas. Sampling zones were centred on campsites or huts for logistical reasons, but were located to ensure a representative range of forest types, elevations and aspects

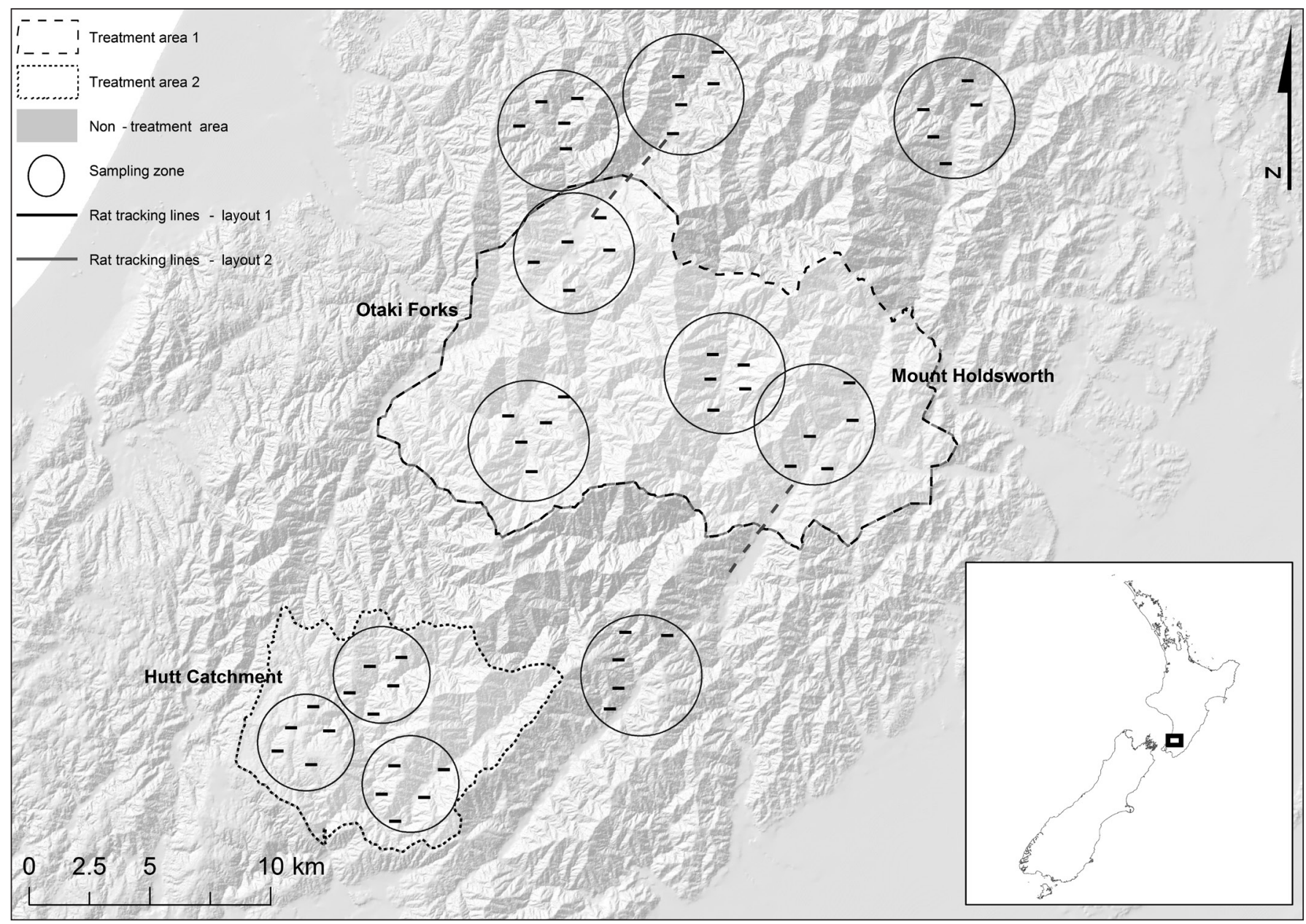

Figure 1. Site map showing Tararua Forest Park (shaded darker grey), the location of treatment and non-treatment areas, 2 to $2.5-\mathrm{km}$ radius sampling zones and rodent tracking tunnel lines. 
were sampled. Within each sampling zone, tracking tunnel line starts were located randomly and the lines oriented east-west. To ensure the tracking tunnel lines were independent, lines were spaced $>500 \mathrm{~m}$ apart, which is larger than the diameter of the typical home range of rats (Clapperton 2006) (Fig. 1).

\section{Layout 2}

An additional 10 tracking tunnel lines were deployed along two $5-\mathrm{km}$ transects straddling the northern and southern boundaries of treatment area 1, in the Otaki and Waiohine river valleys (Fig. 1). Each transect consisted of five tracking tunnel lines. These lines were separated by $>500 \mathrm{~m}$ to ensure independence.

All tracking lines were set over one fine night with Black Trakka (Gotcha Traps Limited, Auckland) ink cards placed on the tunnel floor and baited at either end with peanut butter. The proportion of tunnels per line from which rat footprints were recorded was used as an index of rat abundance. It should be noted $R$. rattus and $R$. novegicus footprints cannot be distinguished on ink cards and tracking scores could include both species, but the majority of tracks are likely to be from $R$. rattus (ship rats), the dominant rat species in North Island forests (Innes 2005).

Tracking tunnels placed following Layout 1 were set on 16 occasions: in December 2009, July 2010, November 2010, November 2010 after 1080 application in treatment area 1, February 2011, May 2011, August 2011, November 2011, January 2012, May 2012, July 2012, September 2012, January 2013, May 2013, September 2013 and February 2014. Tracking tunnels placed following Layout 2 were set on nine occasions: in August 2010, November 2010, February 2011, May 2011, August 2011, November 2011, February 2012, November 2012, and February 2013.

\section{Possum sampling method}

Possum relative abundance was measured using the bite mark index (BMI) outlined by the National Pest Control Agencies (NPCA 2010). For each rodent tracking tunnel line, two possum transects, each with 20 waxtag blocks mounted on plastic triangles (Thomas et al. 2003), were established at c. 10 - $\mathrm{m}$ intervals parallel to the tracking tunnel lines. These were separated by $100 \mathrm{~m}$ end-to-end for independence. On each transect, waxtags were nailed to the base of trees c. $30 \mathrm{~cm}$ above the ground and a flour blaze was used as a lure. Waxtags were left out for three fine nights. Waxtag transects adjacent to rodent tracking lines deployed following Layout 1 were sampled in February 2010, 2011, 2012, and 2013. Waxtag transects adjacent to Layout 2 tracking tunnel lines were sampled during August 2010, November 2010, February 2011, May 2011, August 2011, November 2011, February 2012, November 2012, and February 2013. The proportion of waxtags with possum bite marks per line was used as an index of possum density (BMI).

\section{Seedfall sampling}

Seedfall traps were established under eight randomly selected silver beech (Lophozonia menziesii) trees located on northfacing slopes or terraces in treatment 1 and non-treatment areas. Selected silver beech trees had a diameter at breast height $(\mathrm{DBH})>60 \mathrm{~cm}$ to ensure that mature trees were sampled.

Seedfall traps comprised plastic funnels with a $0.28-\mathrm{m}^{2}$ collection area attached to three wooden stakes (Wardle 1970). These were located on the downhill or northern side of trees with the funnel rim positioned $1.25 \mathrm{~m}$ off the ground c. $2 \mathrm{~m}$ from the tree trunk. From 2011, seedfall traps were set annually between January and late June with knee-length stockings fitted over the narrow end of the funnel. The number of silver beech seed collected per trap was counted and multiplied by the collection area to give the number of seeds collected per square metre.

Additional hard beech (Fuscospora truncata) seedfall data collected following similar methods (Fitzgerald et al. $1996)$ in the nearby Orongorongo Valley $\left(41.4^{\circ} \mathrm{S}, 174.9^{\circ} \mathrm{E}\right)$ were acquired for the period from 2008 to 2013 to provide additional seedfall data and to cover the the period immediately preceding the start of our study.

\section{Data analysis}

All rat tracking tunnel locations were imported into ArcMap 10 (ESRI 2010). Elevation (Barringer et al. 2002), forest type information (Nichols 1976) and distance (m) from treatment edge were calculated for each tracking tunnel location and appended to each tracking tunnel record. Climatic data, mean daily air temperature $\left({ }^{\circ} \mathrm{C}\right)$ and rainfall $(\mathrm{mm})$, for the Tararua Range was obtained from the National Climate Database of New Zealand (NIWA, Masterton Aero Aws, Agent No.:36735) and was also appended to each tracking tunnel record.

The rat tracking indices comprised the number of tunnels with rat tracks present out of a line of ten, typically analysed using a binomial distribution, but the data appeared to be overdispersed (i.e. had a greater than expected variation, in particular more zeroes) compared with a binomial distribution. Thus we assumed the responses were beta-binomially distributed $Y \sim \mathrm{BB}(n, \pi, \sigma)$, which is a compound distribution where the probability of success parameter $\pi$ in the binomial distribution is assumed to be a random variable from a betadistribution $(\pi \sim \mathrm{Be}(\alpha, \beta))$ and the overdispersion parameter $\sigma(=1 / \alpha+\beta)$ represents the level of overdispersion, with large values of $\sigma$ leading to high overdispersion and $\sigma \rightarrow 0$ collapsing to a binomial distribution (Hughes \& Madden 1993; Martin et al. 2011). We used the gamlss (v4.3-4; Stasinopoulos \& Rigby 2007) package in R (v3.0.3; R Core Team 2014) to fit the rat tracking responses (using a logit link function) to the explanatory variables: distance of the tracking line to the uncontrolled area (in $\log (\mathrm{m}))$, the time since control (in weeks) and a potential interaction between distance and time. Other covariates assessed for inclusion in the final model were season (four factor levels: winter, spring, summer autumn), mast seedfall year (binomial factor : mast seedfall defined as $>500$ beech seeds $\mathrm{m}^{-2}$ / no mast defined as $<500$ beech seeds falling $\mathrm{m}^{-2}$; Wardle 1984), elevation (m a.s.1.), forest type (Nichols 1976), the relative abundance of possums (BMI), mean overnight air temperature $\left({ }^{\circ} \mathrm{C}\right)$, and whether it rained on the night the tunnels were open (binomial factor : rain/no rain). The continuous variables distance to uncontrolled area and altitude were mean-centred to assist model convergence. A random effect of line was included in all of the models assessed, since the same lines were measured repeatedly. In all of the models assessed, the overdispersion $(\sigma)$ parameter was assumed to be constant (i.e. an intercept only was fitted) and a log link function was used for the overdispersion parameter. The preferred model was selected from the candidate set of models fitted using the minimum AIC value (Table 1; Akaike 1974). The normalised randomised quantile residuals of the model were inspected to check they were normally distributed with a homogeneous variance.

In order to fit a linear model for the time-since-control effect (which corresponds to exponential growth), we excluded 
Table 1. Akaike Information Criteria (AIC) obtained from a set of models describing the mean probability of a tunnel tracking a rat assuming the number of tunnels tracked (out of 10) followed a beta-binomial distribution. All models included a random effect of line and used a logit link for the mean parameter. The dispersion parameter (not shown) was modelled using a log link and was assumed to be a constant across sites and times.

\begin{tabular}{lcccc}
\hline Fixed effects in mean model & AIC & df & $\Delta$ AIC & Model weight \\
\hline distance * time + elevation + season + mast + possum + temperature & 1841.1 & 12 & 0 & 0.60 \\
distance * time + elevation + season + possum & 1843.4 & 10 & 2.3 & 0.19 \\
distance * time + elevation + season + mast + possum & 1845.1 & 11 & 4.0 & 0.08 \\
distance * time + elevation + season + mast + temperature & 1846.0 & 11 & 4.9 & 0.05 \\
distance * time + elevation + season + mast + possum + rain & 1846.4 & 12 & 5.3 & 0.04 \\
distance * time + elevation + season & 1848.2 & 9 & 7.1 & 0.02 \\
distance * time + elevation + season + mast & 1849.8 & 10 & 8.7 & 0.01 \\
distance * time + elevation + season + mast + rain & 1851.3 & 11 & 10.2 & 0.00 \\
distance * time + elevation & 1854.3 & 6 & 13.2 & 0.00 \\
distance * time + forest type + season + mast + possum + temperature & 1869.0 & 15 & 27.9 & 0.00 \\
distance * time + forest type + season + possum & 1870.2 & 13 & 29.1 & 0.00 \\
distance * time + forest type + season + mast + possum + rain & 1872.9 & 15 & 31.8 & 0.00 \\
distance + time + elevation + season + mast + possum + temperature & 1966.0 & 11 & 124.9 & 0.00 \\
distance + time + elevation + season + mast + possum + rain & 1966.2 & 11 & 125.1 & 0.00 \\
distance + time + elevation + season + possum + temperature & 1967.2 & 10 & 126.1 & 0.00 \\
distance + time + elevation + season + possum + rain & 1967.2 & 10 & 126.1 & 0.00 \\
distance + time + elevation + season + mast + temperature & 1976.2 & 10 & 135.1 & 135.5 \\
distance + time + elevation + season + mast + rain & 1976.6 & 10 & 13 & 0.00
\end{tabular}

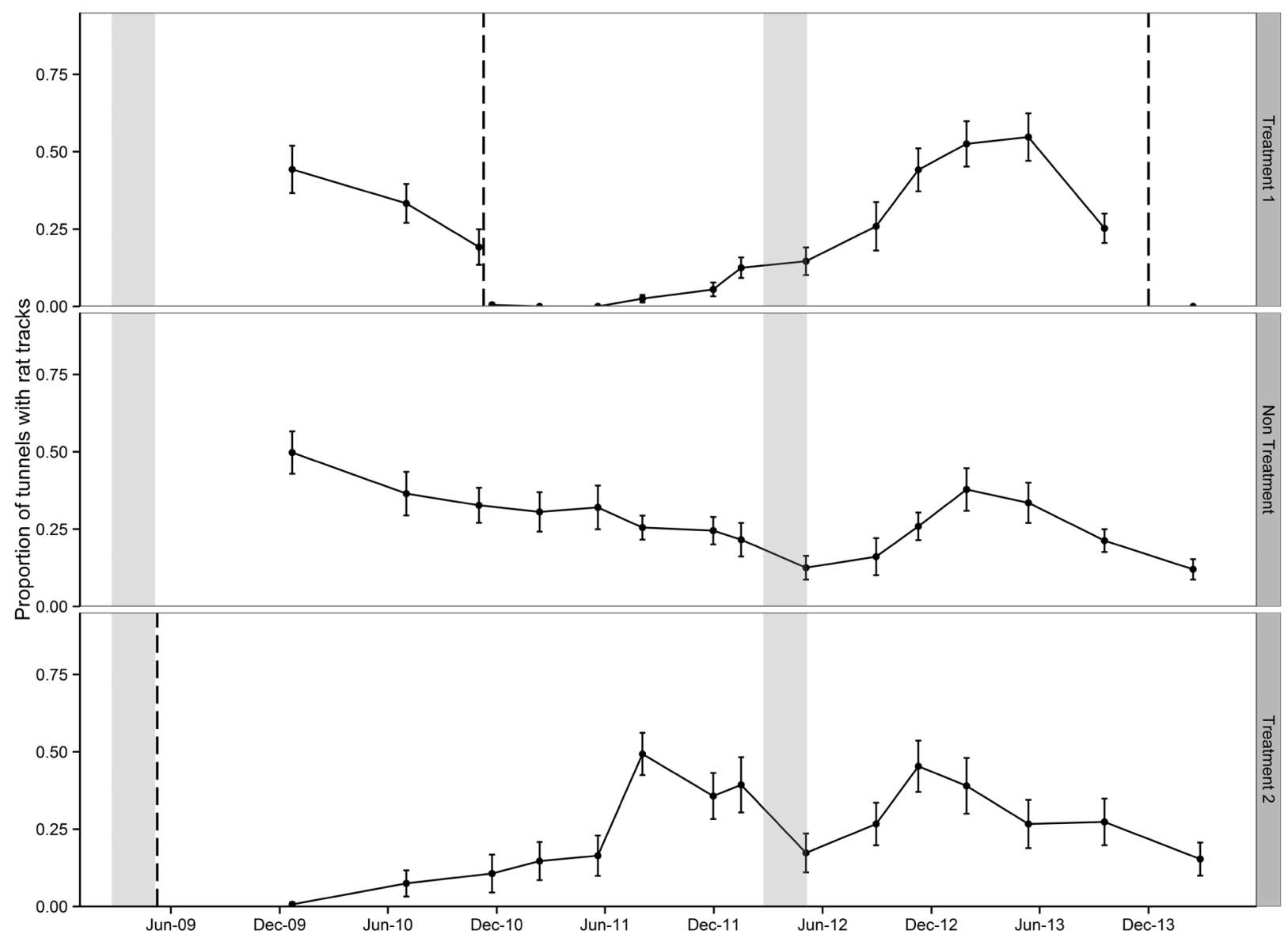

Figure 2. Mean proportion of tracking tunnels with rat tracks per line in the treatment and non-treatment areas from November 2009 to February 2014 using data collected following Layout 1 (error bars = SE, 1080 applications = dashed line, elevated beech seedfall events = grey bands). 
tracking index data $>2.5$ years post-control, at which time growth rates started to taper off and become non-linear (Fig. 2 ). The model dataset included indices from both treatment areas; hence one year post-control corresponds to the calendar year 2011 for treatment 1 and 2010 for treatment 2 .

\section{Results}

Few to no rat tracks were recorded in the treatment areas for 6 months after the aerial application of 1080 to treatment area 2 in May 2009 and treatment area 1 area in November 2010 (Fig. 2). In the non-treatment area during the same periods, rat tracking levels remained relatively high, but fell gradually until May 2012 (Fig. 2). The effect of 1080 application on relative rat abundance persisted for less than 15 months, and 24-30 months after 1080 application, the rat tracking index in treatment 1 and treatment 2 areas exceeded concurrent tracking indices in the non-treatment area (treatment 1 area $t=-2.1137$, d.f. $=35.711, P<0.05$, and treatment 2 area $t=-3.0293$, d.f. $=21.195, P<0.05)$.

From January to June in 2009 and 2012, elevated hard beech seedfall $\left(2656 \pm 782\right.$ seeds $\mathrm{m}^{-2}$ and $1827 \pm 554$ seeds $\mathrm{m}^{-2}$, respectively) was recorded in the Orongorongo Valley, and from January to June 2012, elevated silver beech seedfall $\left(793 \pm 338\right.$ seeds $\left.^{-2}\right)$ was recorded in the Tararua Forest Park. These elevated seedfall events are consistent with definitions of beech mast (Wardle 1984), and contrast with other years in which hard beech and silver beech seedfall was low $(<210$ seeds $\mathrm{m}^{-2}$ and $<40$ seeds $\mathrm{m}^{-2}$, respectively). Our study did not collect rat tracking data before November 2009 so it was not possible to determine whether rat tracking indices responded to the elevated beech seedfall in 2009. However, rat tracking indices in the non-treatment area were highest in spring and summer 2009 and 2012 after elevated seedfall during the preceding summer and autumn. A rapid increase in rat tracking indices was also observed in the non-treatment area after elevated seedfall in 2012 (Fig 2.), and by January 2013 the tracking index in the non-treatment area was higher than in May $2012(\mathrm{t}=-3.097$, d.f. $=29.07, P<0.005)$, but then decreased and by summer 2014, tracking indices in the non-treatment area had returned to levels similar to those recorded in May 2012 (Fig. 2). Pest control was applied to the treatment 1 area again in December 2014 and rat tracking indices, which had declined sharply before 1080 application, declined to zero (Fig. 2).

Few possum bite marks were recorded on waxtags in treatment areas after control, whereas the BMI scores remained relatively high in the non-treatment area (Fig. 3). Although the BMI showed some increase in treatment areas after control, the rate of increase in these areas was slow and BMI scores remained low $(<20 \%)$.

The spatiotemporal distribution of rat tracking indices over the 2.5 years following control revealed a consistent pattern. Within the first $4 \mathrm{~km}$ of the control zone (1-4km: Fig. 4), median tracking indices in the 6 months following control were zero,

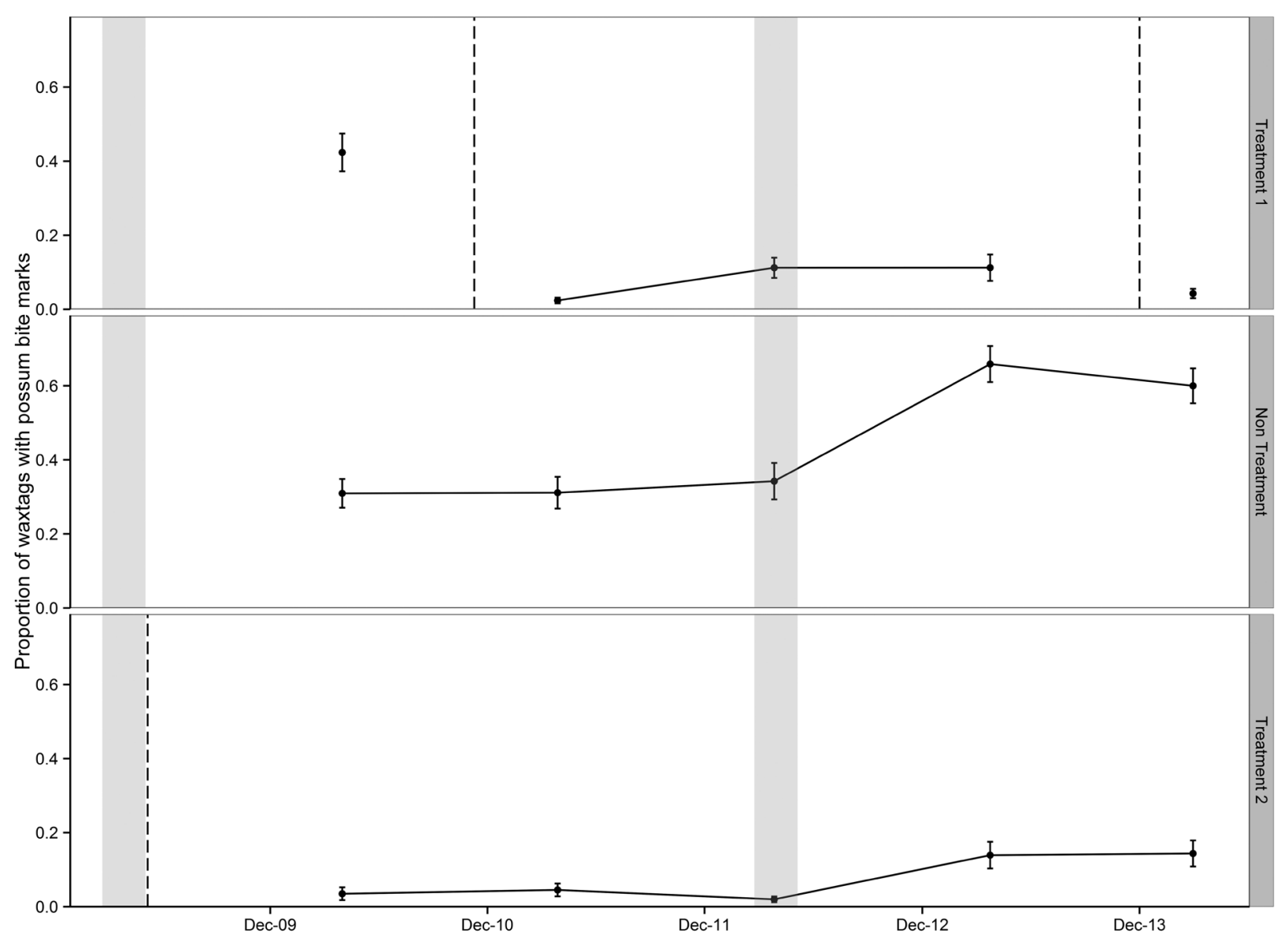

Figure 3. Mean proportion of wax tags bitten by possums per line in the treatment and non-treatment areas from February 2010 to February 2014 using data collected following Layout 1 (error bars = SE, 1080 applications = dashed line, elevated beech seedfall events = grey bands). 


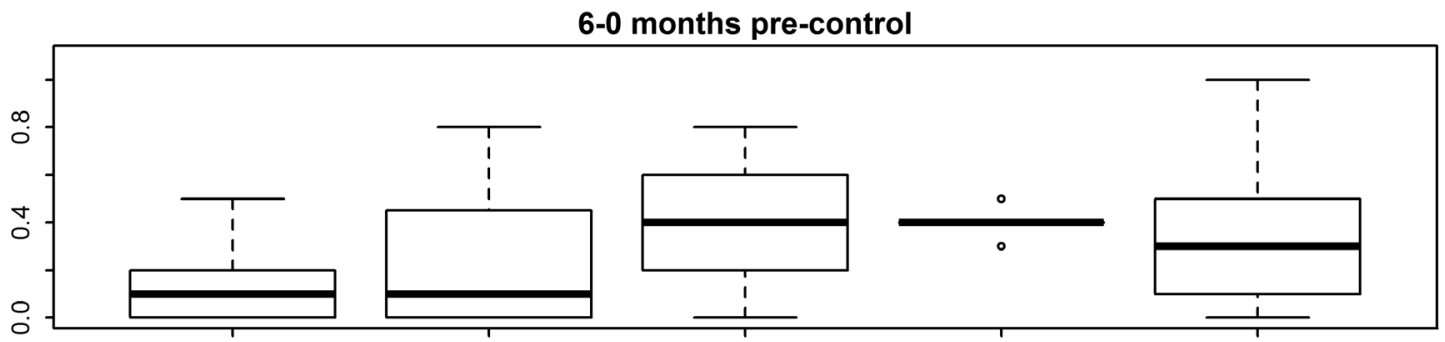

0-6 months post-control

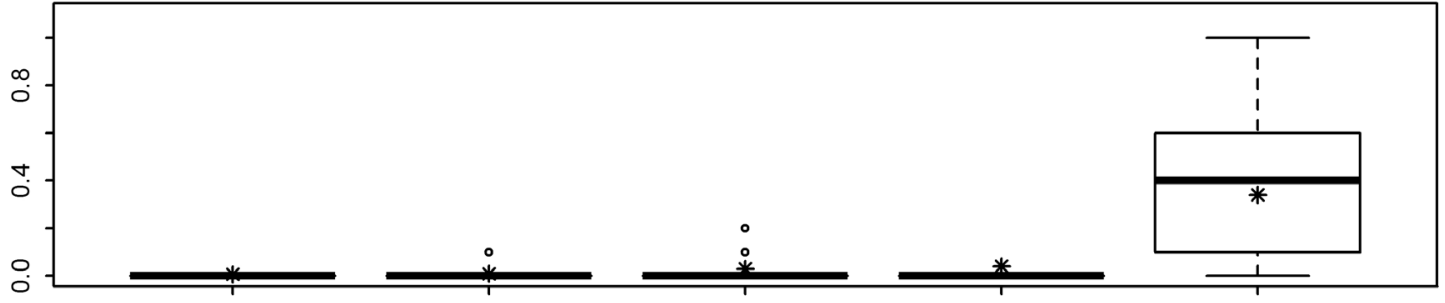

6-12 months post-control

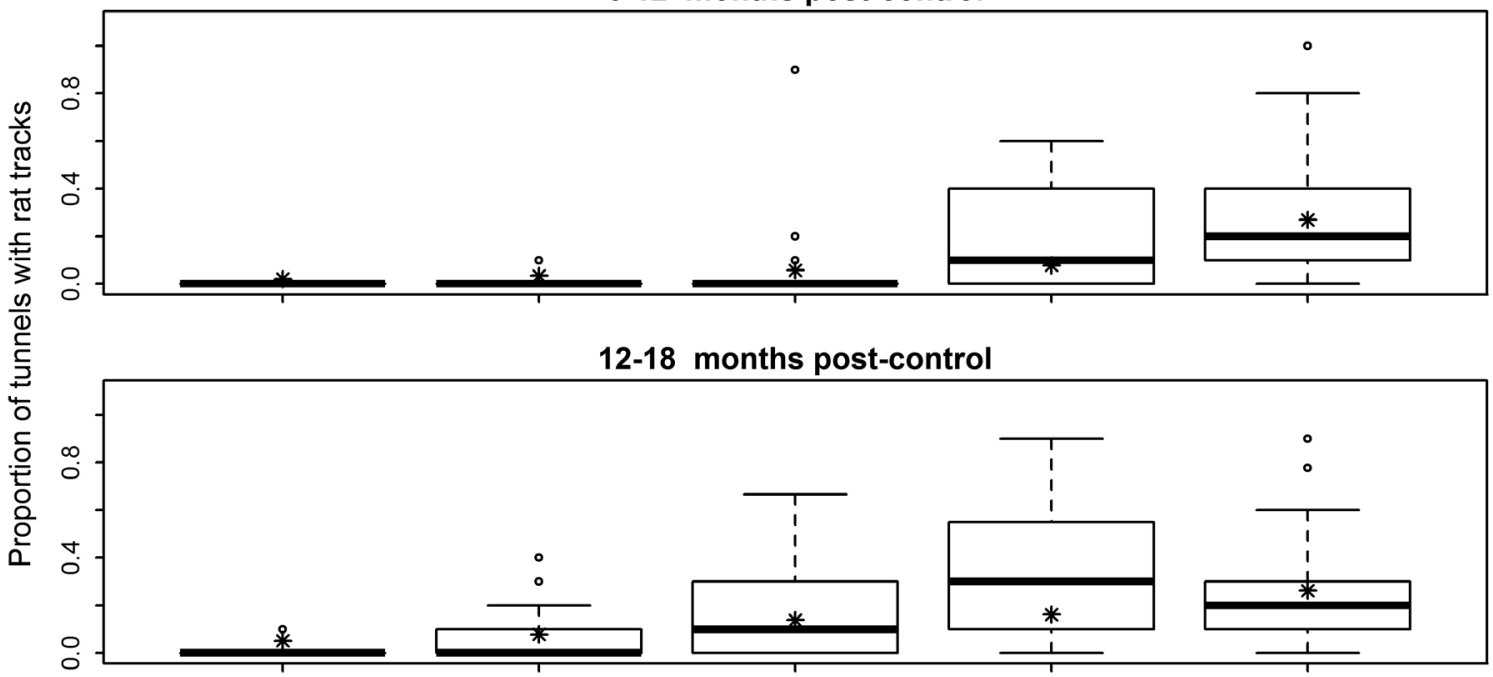

18-24 months post-control

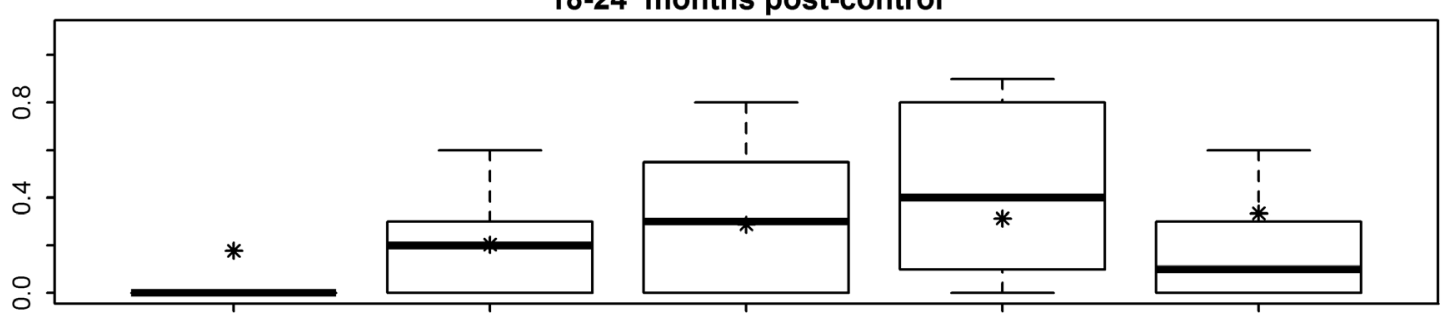

24-30 months post-control

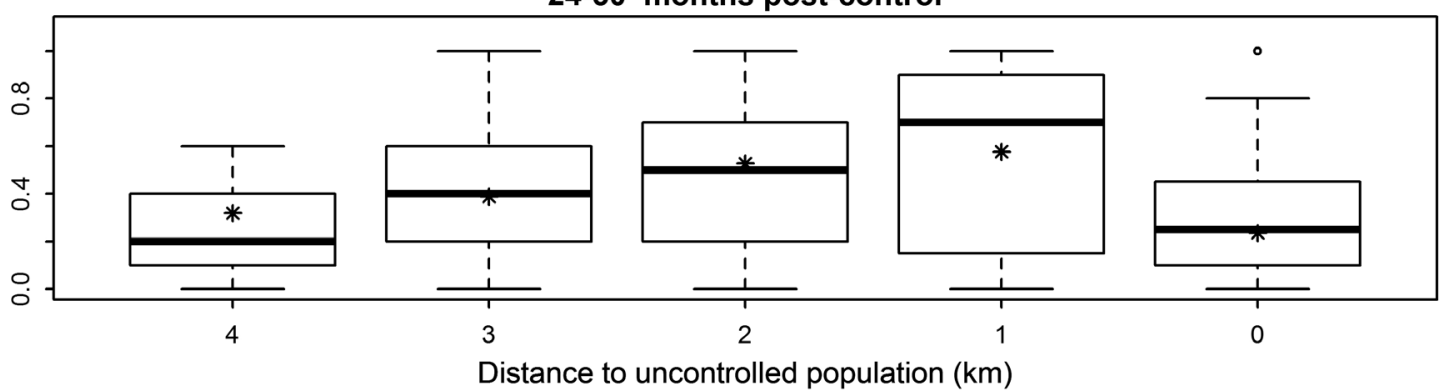

Figure 4. Observed (box and whisker plots: bold line $=$ median, box $=$ interquartile range, whiskers $=$ lowest datum within 1.5 interquartile range of the lower quartile, and the highest datum within 1.5 interquartile of the upper quartile) and fitted (asterisk $=$ median) rat tracking indices with binned time since control (weeks) and distance to the uncontrolled area $(\mathrm{km})$. Note that the model was fitted to post-control rat indices only so no fitted estimates are overlaid on the ' $6-0$ months pre-control' panel. 
Table 2. Linear predictors for probability of a tunnel tracking a rat with weeks since control and distance from an uncontrolled area (logit link). The second intercept is the estimate of the overdispersion parameter (log link) for the beta-binomial distribution.

\begin{tabular}{lrrrr}
\hline Variable & Estimate & SE & t-value & $\operatorname{Pr}(>|\mathrm{t}|)$ \\
\hline Intercept (reference season = winter) & -2.7697 & 0.2016 & -13.74 & $<0.001$ \\
Distance to uncontrolled area (log(m); mean-centred) & -0.4699 & 0.0387 & -12.15 & $<0.001$ \\
Time since control (weeks) & 0.0203 & 0.0023 & 8.97 & $<0.001$ \\
Log distance : time & 0.0052 & 0.0005 & 11.10 & $<0.001$ \\
Possum abundance (-log(1-BMI)) & -0.2256 & 0.0848 & -2.66 & 0.008 \\
Season = spring & 0.1703 & 0.1883 & 0.91 & 0.365 \\
Season = summer & 0.4092 & 0.2364 & 1.73 & 0.841 \\
Season = autumn & -0.5782 & 0.2063 & -2.80 & 0.005 \\
Elevation (m a.s.l.; mean-centred) & -0.0039 & 0.0004 & -9.53 & $<0.001$ \\
Beech mast & 0.0697 & 0.1590 & 0.44 & 0.661 \\
Temp. $\left({ }^{\circ}\right.$ C) & -0.0526 & 0.0212 & -2.48 & 0.016 \\
Line error, SD & 0.0001 & - & - & - \\
\hline Intercept & -1.3089 & 0.1068 & -12.25 & $<0.001$ \\
\hline
\end{tabular}

but beyond the control zone (outside; Fig. 4) tracking indices remained high. Six to 12 months after control, rat tracking indices on lines just inside the control zone $(1 \mathrm{~km})$ increased, whereas lines further away from the control margin $(2-3 \mathrm{~km})$ showed delayed recovery rates at $1-1.5$ years and $1.5-2$ years, respectively. Tracking indices on lines at the centre of the treatment area $(4 \mathrm{~km})$ recovered to levels of approximately $20 \%$ tracking 2-2.5 years after control (Fig. 4).

The best supported mixed-effects model (Table 1) included an interaction term for time since control and distance from the uncontrolled area on rat tracking indices that fitted the spatial pattern of rat recovery (Fig. 4). The interaction term predicted the highest increase in rat tracking indices over time for lines located in the interior of the control zone, declining with proximity to the control margin. Overall, a slightly negative growth rate was estimated for lines located outside of the control area (Table 2). Offsetting this was a negative relationship with distance to the uncontrolled area, resulting in a negative linear predictor for the interior lines, increasing with proximity to the control boundary and positive for lines located outside the control area (Table 2). This reflected the initial (weeks post-control $=0$ ) difference in rat tracking indices, being near-zero on the interior lines and high on lines located outside the control area. Relative possum abundance (BMI) had a negative effect on rat tracking indices (Table 2), and was a feature of the top three ranked models (Table 1). Lines at lower elevations generally had higher frequencies of rat tracking than lines at high elevation, although the elevation covariate was somewhat substitutable with the 'forest type' factor since the two were correlated. For example, the silver beech forest occurred at the highest elevations and had the lowest rat tracking indices; conversely, podocarp-rich forest types occurred at the lowest elevations and had the highest rat tracking indices. Season, air temperature, and mast also influenced tracking indices (Table 2). Autumn had lower tracking indices than other seasons, while beech masting had a positive effect on tracking indices and overnight air temperature had a negative effect (Table 2).

The term describing the variation in the mean probability of rat tracking between the lines was very small (Table 2), but was retained to reflect the structure (repeated measures) of the data. The estimated random effect of line was probably low because allowing the rat tracking response to be overdispersed already accounted for a substantial amount of variation in the rat tracking indices. Transforming the overdispersion coefficient
( $\sigma)$ using $(\rho=\sigma / 1+\sigma)$ gave an estimated pairwise correlation of $\rho=0.21$ between the tunnels within a line, which indicated a potential contagion effect, in that the probability of a tunnel detecting a rat depended on whether other tunnels in the line had also detected one. Extracting the shape parameters for the beta distribution from the fitted coefficients $(\alpha=\pi(1 / \sigma) ; \beta=$ $(1-\pi)(1 / \sigma))$ gave $\alpha=0.16$ and $\beta=2.44$, resulting in a reversedJ-shaped distribution for the mean probability of tracking a rat. This results in a much higher probability of observing zero (out of 10) tunnels tracked than the equivalent binomial response (e.g. 0.73 vs 0.54 , respectively for an overall mean probability of 0.059 ) and better represents the high proportion of zeroes in the data.

\section{Discussion}

Population control of rats appeared effective with few to no rat tracks recorded in treatment areas for 6 months after the aerial application of 1080 . However, rat tracking indices increased rapidly after that, and 24-30 months after 1080 application rat tracking indices in treated areas exceeded those in the nontreatment area. Rat recovery after control followed a consistent spatial pattern with tracking indices increasing initially (6-12 months post-control) at the treatment margins, with recovery delayed by 24-30 months in the centre of controlled areas. This delay in the detection of rats in the interior of the controlled area suggests that immigration rather than in situ breeding initiated the rat population recovery observed on the margins of the pest control area.

After a delay, growth in rat tracking indices was highest in the interior of treatment areas and negative in the uncontrolled areas, leading to peak rat tracking indices in the treatment area exceeding concurrent indices in the non-treatment area. These results align with those of other studies that monitored relative rat and possum abundance following pest control (e.g. Sweetapple et al. 2006; Ruscoe et al. 2011) and may be explained by a release from inter-specific competition with possums (Ruscoe et al. 2011). Sweetapple and Nugent (2007) found a large (55\%) dietary overlap in the fruits and seeds eaten by possums and rats collected from a North Island mixed podocarp-hardwood forest, suggesting potential for competition for food. In our study, we found a significant negative effect of possum relative abundance on rat tracking indices, which supports the competitive release hypothesis. 
However, we also found a substantial control (distance*time) effect, suggesting some other mechanism might be operating. The pest control (1080 application) reduces possum and rat abundance directly and stoats via secondary poisoning, which raises the possibility that it could have been a reduction in the abundance of rats (intra-specific competition) or stoats (predation) that was responsible for the control effects estimated. Ruscoe et al. (2011) discounted the influence of intra-specific competition although they did not explicitly test for it. They did, however, look for a meso-predator release effect (of stoats on rats) but could not detect one. Conversely, Efford et al. (2006) hypothesised a regulatory effect of predators (cats) on ship rats in their long-term study in the Orongorongo Valley (approximately $50 \mathrm{~km}$ south-west of our study site) based on a negative correlation in relative abundance. But they also found evidence of direct density-dependence in the proportion of female rats with young, which they suggested was due to intraspecific competition for invertebrates. Likewise, Sweetapple and Nugent (2007) suggested that a concurrent decline in the proportion of invertebrates in ship rats' diet and the proportion of females breeding could be due to intra-specific competition. We could not test these alternative hypotheses with our index data; although we did monitor stoat abundance, a paucity of detections meant analysis was not possible.

We assessed an alternative explanation for the spatial pattern of rat recovery, that the productivity of rats surviving control was higher at control margins than at the centre of treated areas due to differing environmental conditions. Tracking tunnels at control margins were generally located in river valleys, at lower elevation in mixed-podocarp-broadleaved forest, whereas tracking tunnels further from the treatment margins were more commonly located at higher elevations and in beech forest. This could lead to correlation (and confounding) between the model terms distance from control margin and elevation. However, the fitted coefficients for the effect of distance from the uncontrolled area and elevation of the tracking tunnel lines were not correlated $(R=-0.13)$. Further, including the interaction term (time since control : distance from control margin) and the elevation term in a model alone or in combination did not significantly alter the estimated coefficients of these terms, indicating they were additive to each other rather than confounded.

We suspect the differences in rat tracking indices seen with elevation were due to differences in food availability between different forest types, which vary with elevation (Husheer 2005) and were substitutable with elevation in the model. Lower elevation mixed-podocarp-broadleaved forest has a more temporally-consistent supply of food due to a diversity of fruiting and seeding tree species (Cowan 1990), whereas higher elevation beech forest produces large volumes of seed irregularly during 'mast' events (when seed production is synchronised over large geographic areas), but produces little seed in other years (Wardle 1984).

In their long-term study of ship rat populations in mixed forest in the nearby Orongorongo Valley, Efford et al. (2006) found that seasonal variations in abundance within a year were as large as or larger than changes between years. They could not find any relationship between annual population change and fruit-fall of hīnau or seedfall of hard beech (Fuscospora truncata). In our study, model selection indicated both beech mast and season were predictors of rat abundance indices, although the estimated effect of a mast seedfall event was weak compared to the effect of the autumn season $(7 \%$ increase for mast event and $44 \%$ decrease for autumn on the odds of tracking a rat). The positive influence of beech mast on rodent tracking indices in this study (Fig. 2, Table 2) is consistent with, but less convincing than, that found in other studies conducted in pure beech forest (e.g. King \& Moller 1997; Studholme 2000). Effects of mast seedfall on rat productivity may be less pronounced in mixed forest types (Efford et al. 2006), where rat abundance is consistently higher than in pure beech forest (Innes 2005).

The negative effect of the autumn season fitted in the regression model contrasts with what is known about ship rat biology, whereby rat recruitment over spring and summer leads to a peak in abundance in autumn and early winter (Innes et al. 2001). This also differs with the results of Efford et al. (2006), who found a peak in rat trap catch indices in autumn and winter in nearby mixed-podocarp forest. The unusual effect of season in our study could be an artefact of an unbalanced design, that is, seasons were not spread evenly across all time points since control. But it may also relate to using an index that is sensitive to the assumption that the probability of a rat interacting with a device is constant across monitoring sessions. This assumption may be violated if the bait used to attract rats is more or less attractive at different times of year, for example depending on the (seasonal) availability of preferred food sources, or if variation in rat activity, perhaps due to weather, affects encouter rates. Although we included air temperature as a covariate in the model to account for possible short-term variation in rat detectability due to weather, the season covariate was still selected in the final model and had a strong influence on the odds of tracking a rat.

Evidence that immigration could play a significant role in rat population recovery following pest control has important implications for large-scale pest management. Increasing the size of treatment areas and maximising use of barriers to immigration could prolong treatment persistence by reducing the contribution of immigration to population growth in treated areas following control. Alternatively, ongoing effective perimeter control following the initial knockdown could be implemented to intercept immigrating rats. The trade-offs in cost-effectiveness between the size of the area controlled, its geometry (perimeter to area ratio), the frequency of control, and the extent of perimeter control are poorly known for rodents. However, given that the ecological outcomes desired from rodent control are directly related to the length of time vulnerable native plants and animals are protected from harmful browse and predation pressure (Ruscoe et al. 2013), an optimisation process on outcomes versus costs is needed.

This study suggests that increasing the size of control areas might prolong treatment effect by reducing the contribution of immigration to rat population growth in treatment areas following control. This could improve ecological outcomes of large-scale pest control and may allow treatment frequency to be reduced without compromising ecological gains. However, food availability is likely to influence rates of immigration and in situ breeding following control, and highlights the importance of treatment timing for treatment persistence. If a significant mast seedfall had occurred immediately after 1080 application, treatment persistence may have been reduced due to immigration pressure driven by a rat irruption in the non-treatment area and rapid recovery of surviving rats. As yet, little is known about factors that drive ship rat dispersal. A study of eradication and reinvasion of forest fragments surrounded by pasture (King et al. 2011) showed that a matrix of less suitable habitat was no barrier to ship rat reinvasion of forested fragments, with reinvasion occurring within a 
month. They found a dominance of juvenile males in the reinvading population, suggesting natal dispersal; yet the high connectedness between source and fragment populations and the presence of other age/sex classes also suggest ongoing home range overlap or exploratory movements. In our study there were no barriers to rat movement across the treatment boundary and it is possible that the initial infilling of the edges of the treatment zone was due more to 'home range creep' than long-distance dispersal. There is some evidence that ship rat home ranges are larger at low rat density (Pryde et al. 2005), although how reactive home range size is to the removal of neighbours is unknown. Further research is needed to improve our understanding of interactions between food availability, rat immigration and population growth in treatment areas following control.

Overall we conclude that the spatiotemporal pattern of rat tracking indices after control observed in this study supports the hypothesis that immigration initiates rat recovery. But food resources, such as those associated with beech mast seedfall, are likely to influence rates of recovery. The response in rat tracking indices in this study was likely due to the timing of pest control operations, which preceded or occurred during inter-mast periods. If control interventions had instead preceded mast seedfall events, it is possible spatiotemporal patterns of rat population recovery would have differed from those we observed. Further investigations are needed to improve our understanding of interactions between food availability, rat immigration and population growth in treatment areas after control. However, we contend that increasing the size of pest control areas and aligning control boundaries with topographical barriers, or implementing intensive buffer control ought to extend persistence of pest control at the core of protected areas, by slowing immigration.

\section{Acknowledgements}

We thank Philippa Crisp, Kim Broad, Nikki McArthur and staff from Greater Wellington Regional Council; Jack Mace, Colin Giddy, Sandra Burles, Clint Purches, and Adrian Whiteman from the Department of Conservation; Mike Perry, Dean Clarke, Roger Carran, Caroline Thomson, Grant Morriss, Steve Hough, and Morgan Coleman from Landcare Research who managed logistics and undertook possum and rat sampling. We also thank Graeme Elliott, Josh Kemp, Colin Miskelly, Ben Reddiex, and Wendy Ruscoe for advice on experimental design; and Susan Timmins, Claire Veltman, Roger Pech, and Peter Sweetapple for useful suggestions on the manuscript. This project was funded by Greater Wellington Regional Council, OSPRI, DOC R\&D, and by Core funding for Crown Research Institutes from the Ministry of Business, Innovation and Employment's Science and Innovation Group (contract CO9X0909).

\section{References}

AkaikeH 1974. Anew look at the statistical model identification. IEEE Transactions on Automatic Control 19: 716-723.

Barringer JRF, Pairman D, McNeill SJ 2002. Development of a high-resoultion digital elevation model for New Zealand. Lincoln, Manaaki Whenua Landcare Research.

Blackwell G, Potter M, McLennan J, Minot E 2003. The role of predators in ship rat and house mouse population eruptions: drivers or passengers? Oikos 100: 601-613.

Brown KP, Urlich SC 2005. Aerial 1080 operations to maximise biodiversity protection. Wellington, Science \& Technical Publishing, Department of Conservation.

Clapperton BK 2006. A review of the current knowledge of rodent behaviour in relation to control devices. Science for Conservation 263. Wellington, Department of Conservation.

Cowan P 1990. Fruits, seeds, and flowers in the diet of brushtail possums, Trichosurus vulpecula, in lowland podocarp/mixed hardwood forest, Orongorongo Valley, New Zealand. New Zealand Journal of Zoology 17: 549-566.

Cowan P, Waddington D 1990. Suppression of fruit production of the endemic forest tree, Elaeocarpus dentatus, by introduced marsupial brushtail possums, Trichosurus vulpecula. New Zealand Journal of Botany 28: 217-224.

Dilks P, Willans M, Pryde M, Fraser I 2003. Large scale stoat control to protect mohua (Mohoua ochrocephala) and kaka (Nestor meridionalis) in the Eglinton Valley, Fiordland, New Zealand. New Zealand Journal of Ecology 27: 1-9.

Druce AP 1961. Mountain vegetation of the North Island. N.Z. Soil News 3: 95-107.

Efford M, Fitzgerald B, Karl B, Berben P 2006. Population dynamics of the ship rat Rattus rattus $\mathrm{L}$. in the Orongorongo Valley, New Zealand. New Zealand Journal of Zoology 33: 273-297.

Elliott G, Suggate R 2007. Operation Ark: three year progress report. Christchurch, Southern Regional Office, Department of Conservation.

ESRI 2010. ArcGIS desktop, Release 10. Redlands, CA, Environmental Systems Research Institute.

Fitzgerald B, Daniel M, FitzgeraldA, Karl B, Meads M, Notman P 1996. Factors affecting the numbers of house mice (Mus musculus) in hard beech (Nothofagus truncata) forest. Journal of the Royal Society of New Zealand 26: 237-49.

Foley LA 1984. The geology of basement rocks in the southeastern Tararua Range, North Island, New Zealand. Master's thesis, Victoria University of Wellington, New Zealand. http://researcharchive.vuw.ac.nz/ handle/10063/2289 (accessed 4 August 2015)

Gillies CA, Williams D 2013. DOC tracking tunnel guide v2.5.2: Using tracking tunnels to monitor rodents and mustelids. Wellington, Department of Conservation.

Hughes G, Madden LV 1993. Using the beta-binomial distribution to describe aggregated patterns of disease incidence. Phytopathology 83:759-763.

Husheer SW 2005. Vegetation monitoring, Tararua Forest Park, New Zealand, 1958-85. Wellington, Department of Conservation.

Innes J, Warburton B, Williams D, Speed H, Bradfield $\mathrm{P}$ 1995. Large-scale poisoning of ship rats (Rattus rattus) in indigenous forests of the North Island, New Zealand. New Zealand Journal of Ecology 19: 5-17.

Innes J, Hay R, Flux I, Bradfield P, Speed H, Jansen P 1999. Successful recovery of North Island kokako Callaeas cinerea wilsoni populations, by adaptive management. Biological conservation 87, 201-14.

Innes JG 2005. Ship rat. In: King CM 2005. The handbook of New Zealand mammals, 2nd edn. Melbourne, Oxford University Press.

Innes JG, King CM, Flux M, Kimberley MO 2001. Population biology of the ship rat and Norway rat in Pureora forest 
park, 1983-87. New Zealand Journal ofZoology 28:57-78.

King CM, Moller H 1997. Distribution and response of rats Rattus rattus, R.exulans to seedfall in New Zealand beech forests. Pacific Conservation Biology 3: 143-155.

King CM, Powell RA 2011. Managing an invasive predator pre-adapted to a pulsed resource: a model of stoat (Mustela erminea) irruptions in New Zealand beech forests. Biological Invasions 13: 3039-3055.

King CM, Innes JG, Gleeson D, Fitzgerald N, Winstanley T, O’Brien B, Bridgman L, Cox N 2011. Reinvasion by ship rats (Rattus rattus) of forest fragments after eradication. Biological Invasions 13: 2391-2408.

Martin J, Royle JA, Mackenzie DI, Edwards HH, Kéry M, Gardner B2011. Accounting for non-independent detection when estimating abundance of organisms with a Bayesian approach. Methods in Ecology and Evolution 2: 595-601.

Pryde M, Dilks P, Fraser I 2005. The home range of ship rats (Rattus rattus) in beech forest in the Eglinton Valley, Fiordland, New Zealand: a pilot study. New Zealand Journal of Zoology 32: 139-142.

Miller CJ,Anderson S 1992. Impacts of aerial 1080 poisoning on the birds of Rangitoto Island, Hauraki Gulf, New Zealand. New Zealand Journal of Ecology 16: 103-107.

Nichols JL 1976. A revised classification of the North Island indigenous forests. The New Zealand Journal of Forestry 21: $105-132$.

NIWA (n.d.). CliFlo: NIWA's National Climate Database on the Web.http://cliflo.niwa.co.nz/ (accessed 4August 2015)

NPCA 2010. Possum population monitoring; using the waxtag® method. Wellington, National Possum Control Agencies. http://www.npca.org.nz/images/stories/NPCA/ PDF/a2 monitwaxtag 2010 10.pdf (accessed 4 August 2015)

Powlesland R, Knegtmans J, Marshall I 1999. Costs and benefits of aerial 1080 possum control operations using carrot baits to North Island robins (Petroica australis longipes), Pureora Forest Park. New Zealand Journal of Ecology 23: 149-159.

Editorial board member: Des Smith

Received 10 March 2015; accepted 3 November 2015
Powlesland R, Knegtmans J, Marshall I 2000. Breeding biology of North Island robins (Petroica australis longipes) in Pureora Forest Park. Notornis 47: 97-105.

R Core Team 2014. R; A language and environment for statistical computing. Vienna, Austria, R Foundation for Statistical Computing. http://www.r-project.org/ (accessed 4 August 2015)

Ruscoe WA, Ramsey DS, Pech RP, Sweetapple PJ, Yockney I, Barron MC, Perry M, Nugent G, Carran R, Warne R 2011. Unexpected consequences of control: competitive vs. predator release in a four-species assemblage of invasive mammals. Ecology Letters 14: 1035-1042.

Ruscoe WA, Sweetapple PJ, Perry M, Duncan RP2013. Effects of spatially extensive control of invasive rats on abundance of native invertebrates in mainland New Zealand forests. Conservation Biology 27: 74-82.

Stasinopoulos D M, Rigby RA 2007. Generalized additive models for location scale and shape (GAMLSS) in R. Journal of Statistical Software, 23(7): 1-46. http://www. jstatsoft.org/v23/i07 (accessed 4 August 2015).

Studholme B 2000. Ship rat (Rattus rattus) irruptions in South island beech (Nothofagus) forest. Conservation Advisory Science Notes No. 318, Wellington, Department of Conservation. http://www.doc.govt.nz/documents/ science-and-technical/casn318.pdf (accessed 4 August 2015).

Sweetapple PJ, Nugent G 2007. Ship rat demography and diet following possum control in a mixed podocarp-hardwood forest. New Zealand Journal of Ecology 31: 186-201.

Sweetapple P, Nugent G, Whitford J, Knightbridge P 2002. Mistletoe (Tupeia antarctica) recovery and decline following possum control in a New Zealand forest. New Zealand Journal of Ecology 26: 61-72.

Thomas MD, Brown JA, Maddigan FW, Sessions LA 2003. Comparison of trap-catch and bait interference methods for estimating possum densities. New Zealand Plant Protection: 81-85.

Wardle J 1984. The New Zealand beeches: ecology, utilisation and management. Wellington, New Zealand Forest Service.

Wardle JA 1970. Ecology of Nothofagus solandri. 3. Regeneration. New Zealand Journal of Botany 8: 571-608. 